\title{
Impacto clínico-epidemiológico del virus sincicial respiratorio e identificación de factores de riesgo de enfermedad grave en niños hospitalizados por infección respiratoria aguda Clinical and epidemiological impact of respiratory syncytial virus and identification of risk factors for severe disease in children hospitalized due to acute respiratory tract infection
}

\author{
Dr. Fausto M. Ferolla ${ }^{a}$, Dra. Judith Soffe, Dra. Alicia Mistchenko ${ }^{b}$, \\ Dra. María M. Contrini y Dr. Eduardo L. López ${ }^{a}$
}

\section{RESUMEN}

Introducción: La infección respiratoria aguda grave (IRA) es una causa muy frecuente de internación en pediatría; el virus sincicial respiratorio (VSR) es el principal agente etiológico. Definir en forma precisa la carga de enfermedad que compromete la vida (ECV) por este virus y los factores de riesgo es un desafío. Objetivos: Conocer el impacto del VSR en internados por IRA y describir factores de riesgo de ECV.

a. Hospital de Niños "Dr. Ricardo Gutiérrez", Departamento de Medicina, Programa de Infectología Pediátrica, Universidad de Buenos Aires.

b. Hospital de Niños "Dr. Ricardo Gutiérrez", Laboratorio de Virología.

Correspondencia: Dr. Fausto M. Ferolla: fmferolla@fmed.uba.ar

Financiamiento:

El estudio fue

financiado por una beca de investigación del Gobierno de la Ciudad de Buenos Aires otorgada a la Dra. Judith Soffe y por fondos aportados por la Fundación Argentina de Infectología

Pediátrica.

Conflicto de intereses:

Ninguno que declarar.

Recibido: 3-5-2018

Aceptado: 24-1-2019 http:/ / dx doi.org/10.5546/aap.2019.216

Texto completo en inglés:

http: / / dx.doi.org/10.5546/ aap.2019.eng.216
Cómo citar: Ferolla FM, Soffe J, Mistchenko A, Contrini MM, López EL. Impacto clínico-epidemiológico del virus sincicial respiratorio e identificación de factores de riesgo de enfermedad grave en niños hospitalizados por infección respiratoria aguda. Arch Argent Pediatr 2019;117(4):216-223.

\section{INTRODUCCIÓN}

Las infecciones respiratorias agudas (IRA) son el motivo más frecuente de consulta e internación durante los meses de invierno. ${ }^{1-3}$ En Argentina, se ubican como la tercera causa de mortalidad en los niños de 0 a 5 años de edad. ${ }^{4-8}$

El agente etiológico más frecuente de IRA grave es el virus sincicial respiratorio (VSR). ${ }^{1-3,6,7}$ En los países industrializados, la tasa de hospitalización en los niños infectados con este virus es de, aproximadamente, el $1 \%, 3$ pero la mayoría de los cuadros graves (que incluye el $99 \%$ de los casos fatales) ocurre en los países subdesarrollados. ${ }^{1,2,5-8}$ Las tasas de mortalidad reportadas en distintas partes del mundo varían ampliamente. ${ }^{1,8-10}$

Numerosos factores de riesgo de internación en los niños con IRA han sido descritos. ${ }^{11-16}$ Sin embargo, es escasa la evidencia disponible sobre variables asociadas al desarrollo de una enfermedad que compromete la vida $(E C V)^{6}$ en niños infectados con VSR. Si bien diferentes estrategias están actualmente en estudio, no se cuenta con un tratamiento efectivo 
frente al virus y el manejo continúa siendo de soporte. ${ }^{17-19}$

El objetivo de esta investigación fue caracterizar las infecciones por VSR y compararlas con el resto de las internaciones por IRA; estimar la tasa de hospitalización, la carga de ECV y la mortalidad por VSR, e identificar los factores de riesgo de ECV por VSR.

\section{MATERIALES Y MÉTODOS}

Estudio de vigilancia epidemiológica prospectiva de hospitalización, evolución clínica y mortalidad por infección por VSR en los niños menores de dos años de edad asistidos en el Hospital de Niños “Dr. Ricardo Gutiérrez" de Buenos Aires durante los años 2012 y 2013.

A fin de establecer la carga de enfermedad por VSR, se incorporaron al estudio todos los pacientes menores de 2 años de edad internados con diagnóstico, al momento del ingreso, de IRA grave. Este cuadro fue definido por el desarrollo repentino de tos, taquipnea, sibilancias, tiraje y/o rales, con o sin fiebre, con saturación de oxígeno menor del $93 \%$ al respirar aire ambiental, o la presencia de estos síntomas en los niños menores de un mes independientemente del nivel de saturación. ${ }^{8}$

No se incluyeron aquellos pacientes con síntomas respiratorios de más de 10 días de evolución previa a su internación ni los neonatos que no hubieran sido nunca externados.

Se obtuvieron aspirados nasales dentro de las 24 horas del ingreso de todos los niños incorporados al estudio, como parte de los procedimientos habituales realizados a los internados con esta patología (estándar de cuidado). Estos fueron testeados para obtener el diagnóstico viral por el método de inmunofluorescencia directa (IF) ${ }^{6,7}$

Se obtuvieron datos demográficos, epidemiológicos, clínicos y de laboratorio desde el ingreso y durante la hospitalización usando una ficha específicamente diseñada para tal fin, que incluía los factores de riesgo de internación reportados en la bibliografía:6,11-16 edad, sexo, tabaquismo en el hogar, hacinamiento (más de 3 personas en la misma habitación), edad de la persona a cargo, diagnóstico de asma y/o atopía en los progenitores, desnutrición, anemia, ausencia de lactancia materna, prematurez (edad gestacional menor de 37 semanas), presencia de patología de base. La desnutrición fue definida de acuerdo con el porcentaje de peso para la edad según los percentilos de la Organización Mundial de la Salud (OMS) ${ }^{20}$ y se diagnosticó anemia con niveles de hemoglobina por debajo de -2 desvíos estándar del valor normal para la edad. ${ }^{21} \mathrm{Se}$ definió como ECV la necesidad de cuidados intensivos, con requerimiento de asistencia respiratoria mecánica (ARM) y / o ventilación no invasiva (VNI). Las pautas de manejo habitual de los pacientes no fueron modificadas para la realización de esta investigación.

Este estudio fue aprobado por el Comité de Ética en Investigación de la Institución y por el Consejo de Investigaciones en Salud del Ministerio de Salud de la Ciudad de Buenos Aires. Se obtuvo el consentimiento informado de los padres o tutores previo a la incorporación de los pacientes. Al tratarse de un estudio no experimental ni intervencionista, todos los padres consintieron su participación.

\section{Análisis estadístico}

Se compararon las características de los niños con IRA secundaria a VSR con las de aquellos infectados con otros agentes etiológicos utilizando el test de chi cuadrado y el test $t$ de Student, según correspondiera. Se construyeron modelos multivariados de regresión logística para evaluar los factores de riesgo de ECV tanto en pacientes con IRA en general como en aquellos infectados con VSR. Las variables consideradas de importancia a priori fueron incluidas en estos modelos si el valor de $\mathrm{p}$ en el análisis univariado fue menor de 0,20 o igual. Su calibración (confiabilidad) fue probada mediante el test de Hosmer-Lemeshow, al igual que su capacidad de discriminación, mediante el análisis del área bajo la curva. Se consideraron significativos los valores de $\mathrm{p}$ menores de 0,05. Para el análisis, se utilizó el paquete estadístico Stata, versión 11.2 SE (StataCorp LP, College Station, TX).

\section{RESULTADOS}

Seiscientos veintidós niños se internaron con diagnóstico de IRA y fueron incorporados a la investigación, 144 (el 23,2 \%) eran procedentes de la Ciudad de Buenos Aires y 478 (el 76,8 \%), del conurbano bonaerense. Fueron atendidos previamente por el cuadro que motivó la internación 479 pacientes (el $77 \%$ ); 210 (el 43,8\%) habían consultado en 2 o más oportunidades a una guardia o a un centro de salud. En 372 (el 59,8\%), se diagnosticó VSR [VSR (+)]; de estos, 292 (el 78,5\%) eran previamente sanos.

Las características de la población en estudio se detallan en la Tabla 1, según la positividad para VSR. 
Con respecto a la edad de los pacientes VSR (+), 204 (el 54,8 \%) eran menores de 6 meses, 315 (el 84,7 \%), menores de 1 año (Figura 1). La tasa de hospitalización anual por VSR en menores de 1 año de edad fue de 956 (intervalo de confianza del $95 \%$ [IC $95 \%$ ]: 858-1062) cada 10000 internaciones.

Las manifestaciones clínicas y de laboratorio al momento del ingreso hospitalario se describen en la Tabla 2 y se comparan con aquellas presentadas por los pacientes VSR (-).

El recuento de leucocitos al ingresar no permitió diferenciar a los pacientes VSR (+) de aquellos VSR (-) (Tabla 2). Se les realizaron hemocultivos a 296 niños con IRA, que resultaron positivos en 2 de ellos (el 0,7 \%): Streptococcus pneumoniae en un lactante de 6 meses y Haemophilus influenzae en un lactante de 8 meses, ambos VSR (+), con neumonía confirmada, quienes evolucionaron a una ECV. El recuento de leucocitos al ingresar no permitió predecir bacteriemia en estos pacientes (media: $\left.7300 \pm 2828 / \mathrm{mm}^{3}, \mathrm{p}=0,17\right)$.

Se les indicaron antibióticos a 262 niños VSR (+) (el 70,4 \%); 212 (el 80,9\%), sin imágenes radiológicas compatibles con neumonía

TABLA 1. Características de la población $(n=622)$

\begin{tabular}{lccc}
\hline Característica & $\begin{array}{c}\text { VSR (+) } \\
\text { (n=372) }\end{array}$ & $\begin{array}{c}\text { VSR (-) } \\
\text { (n= 250) }\end{array}$ & Valor de $p$ \\
\hline Edad en meses, m (RIC) & $5(2-9)$ & $6(3-12)$ & $<0,01$ \\
Lactancia materna, n (\%) & $199(53,9)$ & $164(66,1)$ & $<0,01$ \\
Sexo masculino, n (\%) & $203(54,6)$ & $154(61,6)$ & 0,11 \\
Hacinamiento, $\mathrm{n}(\%)$ & $104(28,5)$ & $83(34,7)$ & 0,10 \\
Fumadores en el hogar, n (\%) & $175(47,3)$ & $105(42,0)$ & 0,20 \\
Padres asmáticos, n (\%) & $146(39,6)$ & $105(42,0)$ & 0,47 \\
Desnutrición, $\mathrm{n}(\%)$ & $12(3,2)$ & $7(2,8)$ & 0,78 \\
Prematurez, n $(\%)(\mathrm{a})$ & $41(11,1)$ & $2(0,8)$ & 0,15 \\
DBP, $\mathrm{n}(\%)(\mathrm{b})$ & $5(1,4)$ & $68(28,6)$ & 0,54 \\
Enfermedad de base, $\mathrm{n}(\%)(\mathrm{c})$ & $65(18,2)$ & $48(20,2)$ & $<0,01$ \\
Sibilante recurrente, $\mathrm{n}(\%)(\mathrm{d})$ & $46(12,9)$ & & $<0,01$ \\
\hline
\end{tabular}

VSR: virus sincicial respiratorio; m: mediana; RIC: rango intercuartilo. (a) Prematurez: edad gestacional menor de 37 semanas. (b) DBP: displasia broncopulmonar. (c) Enfermedad de base: inmunodeficiencia congénita o adquirida, cardiopatía congénita, trastorno hematológico, parálisis cerebral, síndrome genético. (d) Sibilante recurrente: antecedente de 3 o más episodios de sibilancias.

FIGURA 1. Edad de los pacientes internados por infección respiratoria aguda y diagnóstico de virus sincicial respiratorio

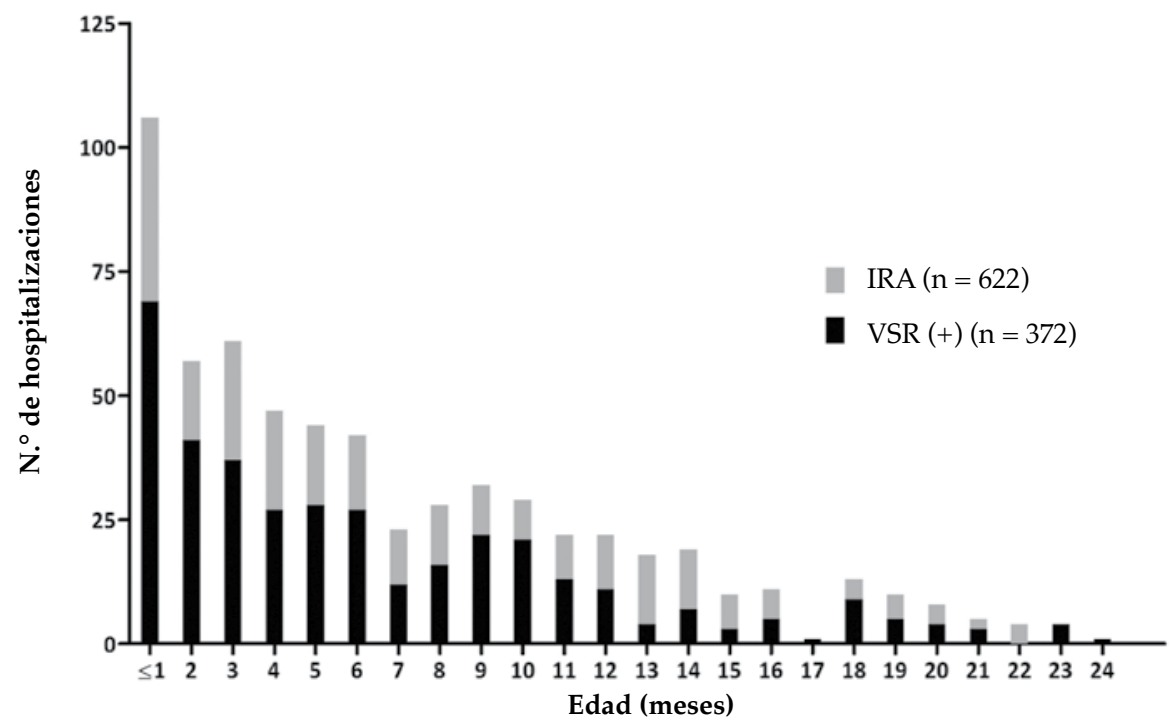

IRA: infección respiratoria aguda; VSR: virus sincicial respiratorio. 
bacteriana, los recibieron durante una mediana de 6 días (rango intercuartílico-RIC-: 3-10). Los más utilizados fueron cefalosporinas de 3 . $^{a}$ generación $(\mathrm{n}=193$, el 73,7 \%), claritromicina $(\mathrm{n}=70$, el $26,7 \%)$ y ampicilina $(\mathrm{n}=59$, el $22,5 \%)$. Se medicaron con corticoides 202 pacientes VSR (+) (el 54,3\%).

Cincuenta y seis de los 78 casos de IRA que desarrollaron una ECV (el 71,8 \%) fueron por VSR. La posibilidad de desarrollar una ECV fue significativamente mayor en los pacientes con
VSR: el 15,1 \% vs. el 8,8 \% en aquellos VSR (-), $\mathrm{p}=0,02$. El análisis multivariado mostró que la infección por este virus y el hacinamiento fueron factores de riesgo de desarrollar ECV en los pacientes internados por IRA (odds ratio ajustado [ORa] 2,045; IC $95 \%$ : 1,15-3,63; $\mathrm{p}=0,014$; y ORa 2,812; IC $95 \%$ : 1,68-4,70; p < 0,001, respectivamente).

Tuvieron ECV por VSR 18 de 110 lactantes menores de 3 meses (el 16,3\%), 22 de 119 niños de entre 3 y 6 meses (el 18,5\%) y 16 de 141 mayores

TABLA 2. Manifestaciones clínicas y de laboratorio al momento del ingreso, según la positividad para el virus sincicial respiratorio $(n=622)$

\begin{tabular}{|c|c|c|c|}
\hline & $\begin{array}{l}\text { VSR (+) } \\
(\mathrm{n}=372) \\
\end{array}$ & $\begin{array}{c}\text { VSR (-) } \\
(\mathrm{n}=\mathbf{2 5 0 )}\end{array}$ & Valor de $p$ \\
\hline \multicolumn{4}{|l|}{ Variables clinicas } \\
\hline Días de evolución previos al ingreso, m (RIC) & $3,5(2-5)$ & $4(2-6)$ & 0,26 \\
\hline Sibilancias, n (\%) & $239(64,2)$ & $163(65,2)$ & 0,80 \\
\hline Pausas respiratorias / apneas, $\mathrm{n}(\%)$ & $22(5,9)$ & $20(8,0)$ & 0,31 \\
\hline Síndrome coqueluchoide, n (\%) & $4(1,1)$ & $3(1,2)$ & 0,88 \\
\hline Fiebre, $\mathrm{n}(\%)^{1}$ & $254(68,3)$ & $162(64,8)$ & 0,37 \\
\hline Vómitos, n (\%) & $92(24,7)$ & $82(32,8)$ & 0,03 \\
\hline Diarrea, $\mathrm{n}(\%)$ & $45(12,1)$ & $33(13,2)$ & 0,68 \\
\hline Neumonía, n (\%) & $50(13,4)$ & $24(9,6)$ & 0,15 \\
\hline \multicolumn{4}{|l|}{ Variables de laboratorio } \\
\hline Recuento de leucocitos $\left(/ \mathrm{mm}^{3}\right),(\mathrm{n})$ media $\pm \mathrm{DE}$ & $(\mathrm{n}=256) 12597 \pm 5658$ & $(\mathrm{n}=146) 13142 \pm 5711$ & 0,36 \\
\hline Anemia, n (\%) & $135 / 251(53,8)$ & $68 / 143(47,5)$ & 0,23 \\
\hline Hemocultivos positivos, $\mathrm{n}(\%)$ & $2 / 187(1,1)$ & $0 / 109$ & - \\
\hline
\end{tabular}

VSR: virus sincicial respiratorio; m: mediana; RIC: rango intercuartilo; DE: desvío estándar; neumonía: diagnosticada por evolución clínica e imagen radiológica de condensación y / o broncograma aéreo.

FIGURA 2. Pacientes internados por infección respiratoria aguda que desarrollaron enfermedad con compromiso de vida, según la edad y la positividad para el virus sincicial respiratorio

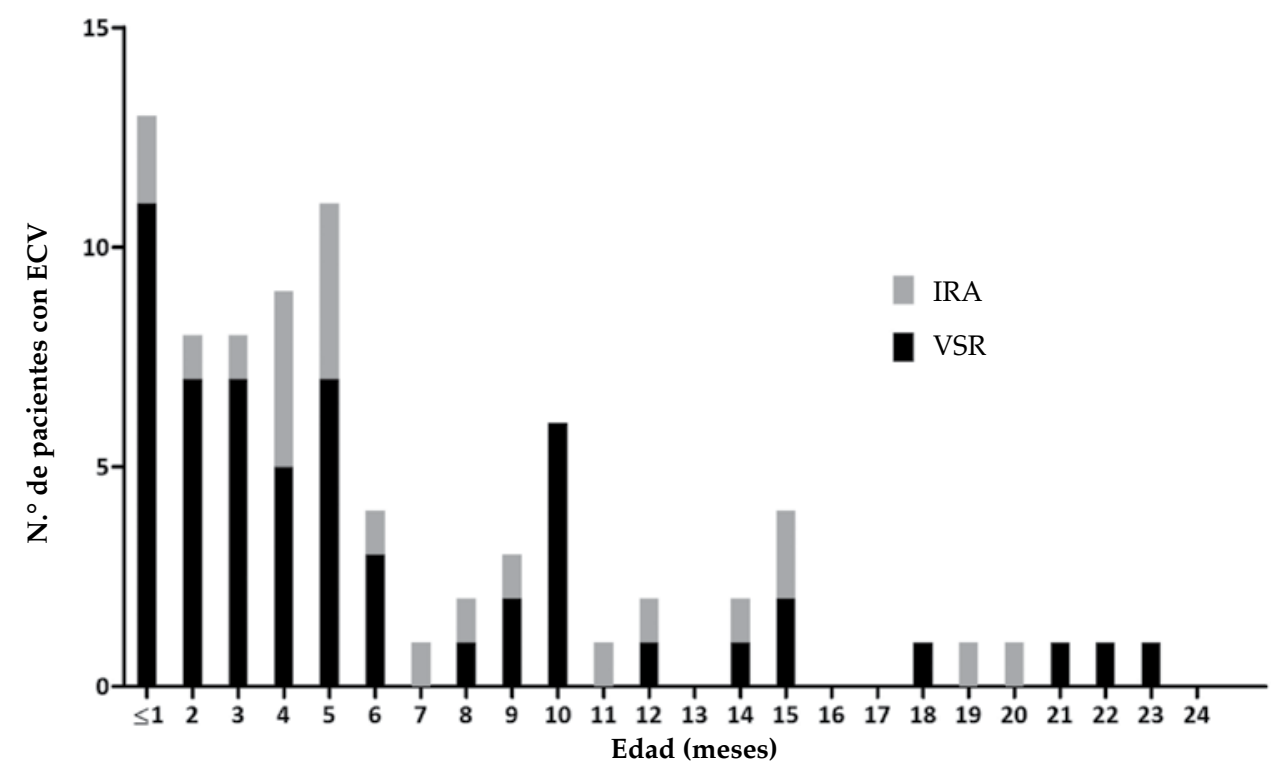

ECV: enfermedad que compromete la vida; IRA: infección respiratoria aguda; VSR: virus sincicial respiratorio. 
de 6 meses (el 11,3\%) (Figura 2). Cuarenta y dos pacientes con ECV por VSR (el $75 \%$ ) eran previamente sanos; de estos, 32 (el 76,2\%) tenían menos de 6 meses de edad. La tasa de hospitalización anual por ECV secundaria a VSR fue de 170 (IC $95 \%$ : 129-220) cada 10000 lactantes internados menores de 1 año.

Cincuenta y cuatro lactantes VSR (+) que desarrollaron ECV (el 96,4 \%) presentaron complicaciones (Tabla 3).

En los pacientes VSR (+), la mediana de días de requerimiento de oxígeno fue de 5 (RIC: $3-7$ ), que aumentó a 10 (RIC: 5-16) en quienes presentaron $\mathrm{ECV}, \mathrm{p}<0,001$. La mediana de días de internación fue de 5 (RIC: 6-9), significativamente mayor en quienes presentaron ECV: 27 (RIC: 18- 46,5), $\mathrm{p}<0,001$.

Tres pacientes de los 6 fallecidos durante el período de estudio estaban infectados por VSR, todos eran menores de 1 año, 2 de ellos menores de 4 meses y con patología de base (displasia broncopulmonar, cardiopatía). La tasa de mortalidad anual por VSR fue de 91 (IC $95 \%$ : 19-266) por cada 10000 lactantes menores de 1 año internados por este virus.

En pacientes VSR (+), tanto el vivir en condiciones de hacinamiento como la lactancia materna ejercieron un efecto diferencial en la evolución de la enfermedad de acuerdo con el género del paciente. Específicamente, el hacinamiento se asoció de modo significativo con el desarrollo de ECV en los varones internados con VSR (ORa 2,36; IC 95 \%: 1,07-5,21; p = 0,03); ninguna otra variable estudiada se asoció a un efecto mórbido similar (Tabla 4). A su vez, la lactancia materna cumplió un rol protector significativo en las niñas (ORa 0,342; IC $95 \%$ : 0,13-0,91; $\mathrm{p}=0,03$ ) (Tabla 4).

\section{DISCUSIÓN}

Los resultados de esta investigación confirman el rol crítico y preponderante del VSR como agente etiológico de IRA grave en los niños pequeños. Las características de la población incluida en el estudio confieren a los resultados una buena representatividad, incluso, en otras regiones del mundo. ${ }^{22}$

Este trabajo, en línea con las estimaciones de un metaanálisis publicado por Nair y col. ${ }^{1}$ y un estudio multicéntrico realizado en el área metropolitana de Buenos Aires, ${ }^{6}$ muestra que la carga de enfermedad por VSR es considerable. Este virus causó más de la mitad de los cuadros de IRA que requirieron internación en menores de 2 años; la mayoría de los niños eran previamente sanos. Se definió como resultado primario la necesidad de cuidados intensivos, con requerimiento de ARM y/o VNI, que se consideró un dato más evaluable y con menos variabilidad que la saturometría, a diferencia de otros estudios multicéntricos que utilizaron el nivel de saturación de oxígeno al momento del ingreso, por la falta de Terapia Intensiva y acceso limitado a los respiradores en algunos de sus centros participantes. ${ }^{6}$

En comparación con el resto de los internados por IRA, la edad de los niños VSR (+) fue significativamente menor, al igual que la menor prevalencia de condiciones mórbidas asociadas o el antecedente de sibilancias recurrentes. Más de la mitad de los pacientes internados por IRA tenía $\leq 6$ meses de edad (el 57,5\%); la mayoría eran menores de 1 año (el 79,1\%; el 84,7\% del total de las admisiones por VSR). No hubo diferencias en el género de los niños internados por IRA, tanto en VSR (+) como en aquellos VSR (-), tampoco entre quienes desarrollaron una ECV. Se ha

TABLA 3. Complicaciones en los pacientes que presentaron enfermedad con compromiso de vida, según la positividad para el virus sincicial respiratorio $(n=78)$

\begin{tabular}{lccc}
\hline Complicaciones, $\mathbf{n}(\boldsymbol{\%})$ & $\begin{array}{c}\text { VSR (+) } \\
(\mathbf{n}=\mathbf{5 4 )}\end{array}$ & $\begin{array}{c}\text { VSR (-) } \\
(\mathbf{n}=\mathbf{2 2})\end{array}$ & Valor de $\mathbf{p}$ \\
\hline Infección asociada al cuidado de la salud & $22(39,3)$ & $13(59,1)$ & 0,12 \\
$\quad$ Neumonía asociada a respirador & $18(33,3)$ & $9(40,9)$ & 0,50 \\
Infección urinaria & $11(20,4)$ & $8(36,4)$ & 0,13 \\
Gastroenteritis & $1(1,8)$ & $4(18,2)$ & 0,03 \\
Atelectasia & $11(20,4)$ & $3(13,6)$ & 0,54 \\
Trombosis venosa profunda & $8(14,8)$ & $4(18,2)$ & 0,90 \\
Neumotórax & $3(5,6)$ & $5(22,7)$ & 0,03 \\
\hline
\end{tabular}

VSR: virus sincicial respiratorio. 
detectado, en los pacientes internados por IRA, una prevalencia considerable de anemia, como así también un preocupante porcentaje de niños que no recibieron leche materna, significativamente más elevado en los hospitalizados por VSR.

Las IRA graves por VSR parecen ser más frecuentes en los países en desarrollo que en las naciones industrializadas. ${ }^{1,6,8,9}$ En un estudio prospectivo de vigilancia de hospitalizaciones por VSR en lactantes de EE. UU., no se observaron muertes asociadas a este virus, ${ }^{23}$ mientras que 3 de 372 niños infectados con VSR fallecieron en nuestro Hospital durante el período de estudio. En el estudio multicéntrico argentino citado, ${ }^{6}$ la mortalidad anual por VSR en menores de 1 año internados fue de 3 (IC $95 \%$ : 1-6) cada 10000 lactantes de esa edad pertenecientes a la región estudiada. Para ejemplificar la magnitud del impacto del VSR, esta tasa cuadruplicó lo reportado para el virus de la influenza A H1N1 en el año de la pandemia en esta población. ${ }^{6} \mathrm{El}$ mismo grupo observó una tasa de mortalidad

TABLA 4. Factores de riesgo para desarrollar enfermedad que compromete la vida en pacientes internados por virus sincicial respiratorio

Factores de riesgo para desarrollar enfermedad que compromete la vida en niñas internadas por virus sincicial respiratorio $(\mathrm{n}=169)$

\begin{tabular}{|c|c|c|c|c|c|c|c|c|}
\hline & \multirow[b]{2}{*}{ ECV } & \multirow[b]{2}{*}{ SIN ECV } & \multicolumn{3}{|c|}{ Análisis univariado } & \multicolumn{3}{|c|}{ Análisis multivariado } \\
\hline & & & OR & IC $95 \%$ & $\mathrm{p}$ & OR & IC $95 \%$ & $p$ \\
\hline \multicolumn{9}{|l|}{ Variables socioeconómicas } \\
\hline Hacinamiento $(\mathrm{n}, \%)$ & $9(40,9)$ & $37(25,7)$ & 2,002 & $0,79-5,07$ & 0,143 & 1,968 & $0,74-5,20$ & 0,173 \\
\hline Tabaquismo en el hogar $(n, \%)$ & $10(45,4)$ & $73(50,0)$ & 0,833 & $0,34-2,05$ & 0,691 & - & & \\
\hline $\begin{array}{l}\text { Edad de la persona a cargo, } \\
\text { años (media, DE) }\end{array}$ & $25,4(6,4)$ & $25,9(7,4)$ & 0,990 & $0,93-1,06$ & 0,765 & - & & \\
\hline \multicolumn{9}{|l|}{ Variables hereditarias } \\
\hline Asma en el padre/la madre $(n, \%)$ & $6(27,3)$ & $56(38,1)$ & 0,609 & $0,22-1,65$ & 0,329 & - & & \\
\hline Atopía en el padre/la madre $(n, \%)$ & $6(27,3)$ & $30(20,5)$ & 1,450 & $0,52-4,02$ & 0,475 & - & & \\
\hline \multicolumn{9}{|l|}{ Variables del niño } \\
\hline Desnutrición (n,\%) & $3(13,6)$ & $4(2,7)$ & 5,645 & $3,48-7,32$ & 0,031 & 3,872 & $0,74-20,3$ & 0,109 \\
\hline Lactancia materna $(\mathrm{n}, \%)$ & $7(31,8)$ & $86(59,3)$ & 0,320 & $0,12-0,83$ & 0,020 & 0,342 & $0,13-0,91$ & 0,032 \\
\hline Edad, meses (media, DE) & $7,6(6,4)$ & $7,0(5,7)$ & 1,016 & $0,94-1,09$ & 0,680 & 1,017 & $0,94-1,10$ & 0,670 \\
\hline Prematurez $(\mathrm{n}, \%)$ & $2(9,1)$ & $17(11,6)$ & 1,032 & $0,95-1,11$ & 0,434 & - & & \\
\hline Patología de base $(n, \%)$ & $5(22,7)$ & $18(12,2)$ & 0,759 & $0,16-3,54$ & 0,725 & - & & \\
\hline Displasia broncopulmonar $(\mathrm{n}, \%)$ & $1(4,8)$ & $3(2,1)$ & 2,300 & $0,23-23,2$ & 0,480 & - & & \\
\hline
\end{tabular}

ECV: enfermedad que compromete la vida; OR: odds ratio; IC: intervalo de confianza; DE: desvío estándar.

Factores de riesgo para desarrollar enfermedad que compromete la vida en varones internados por virus sincicial respiratorio ( $\mathrm{n}=203)$

\begin{tabular}{|c|c|c|c|c|c|c|c|c|}
\hline & \multirow[b]{2}{*}{ ECV } & \multirow[b]{2}{*}{ SIN ECV } & \multicolumn{3}{|c|}{ Análisis univariado } & \multicolumn{3}{|c|}{ Análisis multivariado } \\
\hline & & & OR & IC $95 \%$ & $\mathbf{p}$ & OR & IC $95 \%$ & $p$ \\
\hline \multicolumn{9}{|l|}{ Variables socioeconómicas } \\
\hline Hacinamiento $(\mathrm{n}, \%)$ & $16(48,5)$ & $42(25,3)$ & 2,779 & $1,29-5,98$ & $<, 001$ & 2,362 & $1,07-5,21$ & 0,033 \\
\hline Tabaquismo en el hogar (n,\%) & $20(60,6)$ & $72(42,6)$ & 2,072 & $0,98-4,44$ & 0,061 & 2,001 & $0,40-4,43$ & 0,087 \\
\hline $\begin{array}{l}\text { Edad de la persona a cargo, } \\
\text { años (media, DE) }\end{array}$ & $26,8(6,4)$ & $25,7(6,9)$ & 1,022 & $0,98-1,08$ & 0,437 & - & & \\
\hline \multicolumn{9}{|l|}{ Variables hereditarias } \\
\hline Asma en el padre/la madre $(n, \%)$ & $15(44,1)$ & $69(40,8)$ & 1,144 & $0,54-2,40$ & 0,722 & - & & \\
\hline Atopía en el padre/la madre $(\mathrm{n}, \%)$ & $7(21,9)$ & $47(27,8)$ & 0,727 & $0,29-1,79$ & 0,489 & - & & \\
\hline \multicolumn{9}{|l|}{ Variables del niño } \\
\hline Desnutrición (n,\%) & 0 & $5(3,0)$ & - & & & - & & \\
\hline Lactancia materna $(\mathrm{n}, \%)$ & $14(42,4)$ & $92(54,4)$ & 0,617 & $0,29-1,31$ & 0,209 & 0,660 & $0,30-1,45$ & 0,301 \\
\hline Edad, meses (media, DE) & $4,7(4,0)$ & $6,1(5,1)$ & 0,932 & $0,85-1,02$ & 0,120 & 1,017 & $0,94-1,10$ & 0,670 \\
\hline Prematurez $(\mathrm{n}, \%)$ & $3(9,1)$ & $19(11,2)$ & 0,789 & $0,22-2,84$ & 0,717 & 0,943 & $0,86-1,03$ & 0,186 \\
\hline Patología de base $(\mathrm{n}, \%)$ & $9(26,5)$ & $33(19,5)$ & 1,484 & $0,63-3,48$ & 0,364 & - & & \\
\hline Displasia broncopulmonar $(\mathrm{n}, \%)$ & $1(3,0)$ & 0 & - & & & - & & \\
\hline
\end{tabular}

ECV: enfermedad que compromete la vida; OR: odds ratio; IC: intervalo de confianza; DE: desvío estándar. 
anual atribuible al VSR de 9,4 cada 10000 nacidos vivos (IC $95 \%$ : 5,5-13,3), que constituyó la primera causa de mortalidad fuera del período posneonatal. $^{8}$

No se identificaron características clínicas ni de laboratorio que permitieran diferenciar a los niños VSR (+) del resto. Si bien la infección bacteriana secundaria en los pacientes con VSR ha sido descrita ${ }^{24}$ y también observada en nuestra investigación, resulta llamativo el elevado número de pacientes infectados con este virus que recibieron antibioticoterapia prolongada sin indicios concluyentes de neumonía consolidante. Varios estudios clínicos demostraron la inutilidad del uso de macrólidos y corticoides en los lactantes con bronquiolitis. ${ }^{19,25}$

La mayoría de los niños internados por IRA que desarrollaron ECV eran previamente sanos y estaban infectados por VSR.

En un análisis multivariado que incluyó los factores de riesgo de internación tradicionales, ${ }^{6}$ dos variables influyeron significativamente en el riesgo de desarrollar una ECV por VSR: el vivir en condiciones de hacinamiento y la falta de lactancia materna. La influencia de un medioambiente con una alta carga bacteriana en la gravedad de las infecciones por VSR ya ha sido reportada. ${ }^{6,26} \mathrm{El}$ hacinamiento estaría vinculado a una mayor exposición a lipopolisacárido bacteriano. Hasta la fecha, no se encontraron estudios que hayan descrito esta condición como un factor de riesgo significativo para desarrollar $\mathrm{ECV}$, específicamente, en los lactantes varones hospitalizados por VSR. Los fenómenos que llevan a esta asociación diferencial según el género requieren mayores estudios. A su vez, el rol protector de la lactancia materna resultó particularmente significativo en las niñas, lo cual coincidió con lo evidenciado en otros estudios. ${ }^{27}$

La presente investigación posee ciertas limitaciones. Las infecciones por VSR tienen un pico cada 4 o 5 años, ${ }^{6}$ y un período de estudio que incluyera más inviernos podría detectar una mayor o menor carga de enfermedad. De todas maneras, las tasas reportadas no difieren mucho de aquellas descritas desde $2008^{6,28} \mathrm{y}$, por lo tanto, nuestros datos, probablemente, reflejen el típico impacto de las IRA asociadas a VSR en nuestro medio. Es un estudio basado en niños internados en un solo centro; las diferencias regionales en exposiciones medioambientales, variaciones genéticas o hábitos culturales podrían influenciar en los resultados. Finalmente, el impacto de las variables estudiadas en el riesgo de internación no ha podido ser analizado por el diseño del estudio.

Las estrategias de salud pública dirigidas a modificar los factores de riesgo descritos y otras variables que pudieran identificarse en un futuro deberían ser exploradas con el objeto de disminuir el impacto de las IRA que comprometen la vida. A su vez, el conocimiento de los factores vinculados a la extrema gravedad podría contribuir a dirigir medidas preventivas en forma individualizada y a decidir la internación precoz y oportuna de aquellos pacientes con mayor riesgo.

\section{CONCLUSIONES}

El VSR fue el agente etiológico más frecuente de las IRA graves: causó más de la mitad del total de casos y afectó, en su mayoría, a pacientes menores de 1 año previamente sanos. Los varones que vivían en condiciones de hacinamiento y las niñas que no recibían leche materna constituyeron el grupo con mayor riesgo de ECV.

\section{REFERENCIAS}

1. Nair H, Nokes DJ, Gessner BD, Dherani M, et al. Global burden of acute lower respiratory infections due to respiratory syncytial virus in young children: a systematic review and meta-analysis. Lancet. 2010;375(9725):1545-55.

2. Moïsi JC, Nokes DJ, Gatakaa H, Williams TN, et al. Sensitivity of hospital-based surveillance for severe disease: a geographic information system analysis of access to care in Kilifi district, Kenya. Bull World Health Organ. 2011;89(2):102-11.

3. Carroll KN, Gebretsadik T, Griffin MR, Wu P, et al. Increasing burden and risk factors for bronchiolitis-related medical visits in infants enrolled in a state health care insurance plan. Pediatrics. 2008;122(1):58-64.

4. Ministerio de Salud de la Nación Argentina. Abordaje integral de las infecciones respiratorias agudas. Guía para el equipo de salud. 2.a ed. 2011. [Consulta: 1 de febrero de 2019]. Disponible en: http: / / www.msal.gob.ar/images / stories / bes / graficos / 0000000263 cnt-guia-integralinfecciones-resp-agudas.pdf.

5. Bossio JC. Mortalidad por neumonía en la niñez. ¿Qué está pasando? Arch Argent Pediatr. 2006;104(2):102-5.

6. Ferolla FM, Hijano DR, Acosta PL, Rodríguez A, et al. Macronutrients during pregnancy and life-threatening respiratory syncytial virus infections in children. Am J Respir Crit Care Med. 2013;187(9):983-90.

7. Lucion MF, Juarez M del V, Viegas M, Castellano V, et al. Virus respiratorio sincicial: patrón clínico epidemiológico en niños internados en un hospital pediátrico durante los años 2000-2013. Arch Argent Pediatr. 2014;112(5):397-404.

8. Geoghegan S, Erviti A, Caballero MT, VAllone F, et al. Mortality due to respiratory syncytial virus: burden and risk factors. Am J Respir Crit Care Med. 2017;195(1):96-103.

9. Lozano R, Naghavi M, Foreman K, Lim S, et al. Global and regional mortality from 235 causes of death for 20 age groups in 1990 and 2010: a systematic analysis for the Global Burden of Disease Study 2010. Lancet. 2012;380(9859):2095-128.

10. Weinberg GA, Erdman DD, Edwards KM, Hall CB, et al. Superiority of reverse transcription polymerase chain reaction to conventional viral culture in the diagnosis of acute respiratory tract infections in children. J Infect Dis. 
2004;189(4):706-10.

11. Simoes EA. Environmental and demographic risk factors for respiratory syncytial virus lower respiratory tract disease. J Pediatr. 2003;143(5 Suppl):S118-26.

12. Kristensen K, Hjuler T, Ravn H, Simöes EA, Stensballe LG. Chronic diseases, chromosomal abnormalities, and congenital malformations as risk factors for respiratory syncytial virus hospitalization: a population based cohort study. Clin Infect Dis. 2012;54(6):810-7.

13. Carroll KN, Gebretsadik T, Griffin MR, Dupont WD, et al. Maternal asthma and maternal smoking are associated with increased risk of bronchiolitis during infancy. Pediatrics. 2007;119(6):1104-12.

14. Vidaurreta SM, Marcone ND, Ellis A, Ekstrom J, et al. Infección respiratoria aguda viral en niños menores de 5 años. Estudio epidemiológico en dos centros de Buenos Aires, Argentina. Arch Argent Pediatr. 2001;109(4):296-304.

15. García CG, Bhore R, Soriano-Fallas A, Trost M, et al. Risk factors in children hospitalized with RSV bronchiolitis versus non-RSV bronchiolitis. Pediatrics. 2010;126(6):e1453-60.

16. Simoes E. Respiratory syncytial virus infection. Lancet. 1999;354(9181):847-52.

17. Luongo C, Winter CC, Collins PL, Buchholz UJ. Increased genetic and phenotypic stability of a promising liveattenuated respiratory syncytial virus vaccine candidate by reverse genetics. J Virol. 2012;86(19):10792-804.

18. Polack FP. The changing landscape of respiratory syncytial virus. Vaccine. 2015;33(47):6473-8.

19. Mazur N, Martinón-Torres F, Baraldi E, Fauroux B, et al. Lower respiratory tract infection caused by respiratory syncytial virus: current management and new therapeutics. Lancet Respir Med. 2015;3(11):888-900.
20. World Health Organization. The WHO child growth standards. [Consulta: 1 de diciembre de 2017]. Disponible en: http:/ / www.who.int/childgrowth/standards/en.

21. Comité Nacional de Hematología, Sociedad Argentina de Pediatría. Anemia ferropénica. Guía de diagnóstico y tratamiento. Arch Argent Pediatr. 2009;107(4):353-61.

22. Stein R. Severe respiratory syncytial virus bronchiolitis in underserved populations and the association with unhealthy diets during pregnancy. Am J Respir Crit Care Med. 2013;187(9):908-9.

23. Hall CB, Weinberg GA, Iwanel MK, Blumkin AK, et al. The burden of respiratory syncytial virus infection in young children. N Engl Med. 2009;360(6):588-98.

24. Farley R, Spurling GK, Eriksson L, del Mar CB. Antibiotic for bronchiolitis in children under two years of age. Cochrane Database Syst Rev. 2014(10):CD005189.

25. Mc Callum G, Chang AB, Grimwood, K. Further clinical trials on macrolides for bronchiolitis in infants are unnecesary. J Allergy Clin Immunol. 2015;136(4):1134-5.

26. Caballero MT, Serra ME, Acosta PL, Marzec J, et al. TLR4 genotype and environmental LPS mediate RSV bronchiolitis through Th2 polarization. J Clin Invest. 2015;125(2):571-82.

27. Libster R, Bugna Hortoneda J, Laham FR, CAsellas JM, et al. Breastfeeding prevents severe disease in full term female infants with acute respiratory infection. Pediatr Infect Dis J. 2009;28(2):131-4.

28. Ministerio de Salud de la Nación. Dirección Nacional de Epidemiología y Análisis de la Situación de Salud. Boletín Integrado de Vigilancia. 2013;199(SE49). [Consulta: 1 de diciembre de 2017]. Disponible en: http://www.msal. gob.ar/images / stories / boletines / boletin-integradovigilancia-N199-SE49.pdf. 